\title{
Evaluation of CT Image Guided Radiofrequency Ablation in the Management of Painful Bone Metastases Originating from NSCLC
}

\author{
Evanthia Botsa ${ }^{1 *}$, Ioanna Thanou ${ }^{2}$, Antonia Koundouraki ${ }^{2}$ and Loukas Thanos ${ }^{2}$ \\ ${ }^{1}$ First Pediatric Clinic, Agia Sofia Children's Hospital, National and Kapodistrian University of Athens, Thivon \& Levadias, Goudi, Athens, Greece \\ ${ }^{2}$ Department of Medical Imaging and Interventional Radiology, Sotiria General Hospital for Chest Diseases, Mesogeion, Athens, Greece
}

Received: February 22, 2017; Accepted: May 10, 2017; Published: May 31, 2017

*Corresponding author: Evanthia Botsa, Consultant First Pediatric Clinic, Agia Sofia Children's Hospital, National and Kapodistrian University of Athens, Thivon \& Levadias, Goudi, Athens, Greece, Phone:+306945559966;E-mail: vadoula@hotmail.com

\begin{abstract}
Background: Pain palliation in patients with bone metastases is of great importance. The ideal treatment method has to be fast, safe, effective and tolerable for the patient.

Objective: Evaluation of efficacy and safety of computed tomography (CT) guided radiofrequency ablation (RFA) as a treatment method of painful bone metastases originating from NSCLC.

Materials and methods: A total of thirty two patients with painful bone metastases originating from NSCLC were included in our study (median age 67; range 35-88 years). Lesion diameter was between 2 and $6 \mathrm{~cm}$ (mean \pm SD: $2.8 \pm 2 \mathrm{~cm}$ ). Pain was assessed in all patients with the Brief Pain Inventory (BPI). All patients were treated with RFA under CT guidance, under conscious sedation. RFAs were performed either with RITA Model $1500 \AA$ electrosurgical generator with a seven-array multitined electrode or AMICA electrosurgical generator, depending on the lesion's size. Mean ablation time was 9.5 minutes. Technically successful ablation was considered when lesion was completely covered according to protocol. After each session a CT scan was performed in order to exclude complications. Patients were hospitalised up to 24 hours for clinical monitoring. Post-ablation assessment with BPI score and report of the use of analgesics was performed with telephone interview one, four and eight weeks after the ablation.
\end{abstract}

Results: We observed significant decrease in the mean past day BPI score for worst pain, for average pain and for pain interference during daily life in comparison to pre procedural symptoms $(\mathrm{P}<0.001$, paired t-test), one, four and eight weeks after treatment. There was also a marked decrease in the use of analgesics. None complication occurred.

Conclusions: RFA appears to be a promising treatment method for painful bone metastases originating from NSCLC as it is a safe, fast, minimal invasive method with high efficacy and security. Pain

Keywords: Radiofrequency ablation; Bone metastases; NSCLC;

\section{Introduction}

Painful bone metastases are a common cause of morbidity in patients with metastatic cancer, especially when combined with neural compression and pathologic fractures. Up to seventy percent of solid cancers are associated with bone metastases. Lung cancer is one of the most common solid tumors to develop metastases to bone [1]. Prognosis of patients with metastatic lung cancer to bones is short, usually less than 6 months [2]. Treatment of local disease aims to the reduction of pain and improvement of life quality thus it must be fast, safe, effective and tolerable of these patients who, in most cases, have short life expectancy. A number of treatment methods such as radiotherapy, surgery, chemotherapy, and medical therapy with analgesics and bisphosphonates are available with variable success and complications. Radio Frequency Ablation (RFA) is a relatively new method for the treatment of painful bone metastases. RFA has been employed for the treatment of hepatocellular carcinoma, liver metastases, renal and lung tumours, as well as for the treatment of osteoid osteoma, for which it has become the treatment of choice. Competing methods include chemical ablation (with ethanol or acetic acid) and thermal therapies, such as with laser, microwave, ultrasound and cryoablation [3]. The aim of this study was to demonstrate the effectiveness and safety of computed tomography guided RFA of painful bone metastases originating from NSCLC.

\section{Materials and methods}

A total of 32 patients with bone metastases from NSCLC were concluded in our study. There were 18 men and 14 women. Their ages ranged between 35 and 88 years (mean \pm standard deviation: $67 \pm 10.2$ years). All patients selected to undergo a radiofrequency ablation had Brief Pain Inventory (BPI) score above 4 (scale range $0-10$ ), weren't appropriate candidates for irradiation or surgery, didn't respond or had major complications to chemotherapy and/or radiation therapy, had life expectancy greater than two 
months, or preferred this treatment over other alternatives. Bone metastases were diagnosed by bone scintigraphy and spiral CT. All treated lesions were osteolytic with a combination of bone destruction and a soft tissue mass. The diagnosis was confirmed with a core needle biopsy obtained at the beginning of the procedure. Tumor characteristics and topographical distribution are reported in table 1.

\begin{tabular}{|c|c|c|c|}
\hline \multicolumn{1}{|c|}{ Table 1: Lesion characteristics } \\
$\begin{array}{c}\text { Site of } \\
\text { metastases }\end{array}$ & $\begin{array}{c}\text { Number of } \\
\text { patients }\end{array}$ & $\begin{array}{c}\text { Lesion size } \\
(\mathrm{cm})\end{array}$ & $\begin{array}{c}\text { Number of } \\
\text { patients }\end{array}$ \\
\hline Pelvis & 11 & $<3$ & 11 \\
\hline Ribs & 7 & $3-5$ & 16 \\
\hline Sacrum & 6 & $>5$ & 5 \\
\hline Femur & 2 & & \\
\hline Spine & 4 & & \\
\hline Scapula & 2 & & \\
\hline Tibia & 2 & & \\
\hline
\end{tabular}

Pain was assessed with the BPI on a numerical rating scale where 0 indicates no pain, and 10 indicates worst pain imaginable. The day before the procedure we recorded BPI score for worst pain, for average pain, for pain interference during daily life and the use of analgesics. Post-ablation assessment with BPI score and report of the use of analgesics was performed with telephone interview one, four and eight weeks after the ablation.

Before the procedure all patients were informed and written consent was obtained. Pre-procedural blood tests included measurements of hemoglobin concentration, international normalized ratio, partial thromboplastin time and platelet count. Exclusion criteria included only coagulopathy, INR $>1.5$ or a platelet count of less than $60,000 / \mathrm{mm}^{3}$. The procedure was performed under conscious sedation (administration of 3 $\mathrm{mg}$ of bromazepam $\mathrm{PO}$ and $50 \mathrm{mg}$ of pethidine hydrochloric acid IM, 45 min prior to the procedure). All patients were placed in the appropriate position (prone, supine, or lateral, depending on the site of the lesion) and a scan of the desired area with a $5 \mathrm{~mm}$ slice thickness was performed. The imaging modality of choice for the percutaneous electrode guidance was spiral CT (Somatom Emotion Duo System, Siemens). All procedures were performed by the same interventional radiologist (LT) with a 20year experience in CT-guided percutaneous interventions. The skin was prepared with povidone iodine $(10 \%)$ solution and local anaesthesia ( $15 \mathrm{~mL}$ of $2 \%$ lidocaine hydrochloride solution) was administered. RFA was performed with a RITA Model 1500X® electrosurgical generator, $250 \mathrm{~W}$ power, $460 \mathrm{kHz}$ frequency (RITA Medical Systems, Mountain View, CA, USA) and a seven-array, 2 to $3 \mathrm{~cm}$ multitined electrode for lesions over $3 \mathrm{~cm}$, or AMICA electrosurgical generator, $200 \mathrm{~W}$ power, $450 \mathrm{kHz}$ frequency (HS Hospital Service, Aprilia, Italy) for lesions less than $3 \mathrm{~cm}$ in diameter. The electrode tip was inserted to approximately 1 $\mathrm{cm}$ from the centre of the target [Figure1]. The electrodes were then deployed slowly, taking into account the need to ablate the lesion completely. Lesions smaller than $4 \mathrm{~cm}$ were treated with one placement of the ablation electrode while lesions larger than $4 \mathrm{~cm}$ required up to two placements. $\mathrm{RF}$ ablation time was 7-12 min at an energy of 90-110 W, with the target goal temperature set to $80-1100 \mathrm{C}$. Technically successful ablation is considered to be when the lesion is treated according to protocol and completely covered. After each session a CT examination was performed in order to evaluate immediate response and to exclude complications. Patients were clinically observed up to 24 hours and analgesics were administered if required. Patients were dismissed provided that no complication occurred and pain was re-evaluated with the BPI score before patient's discharge.
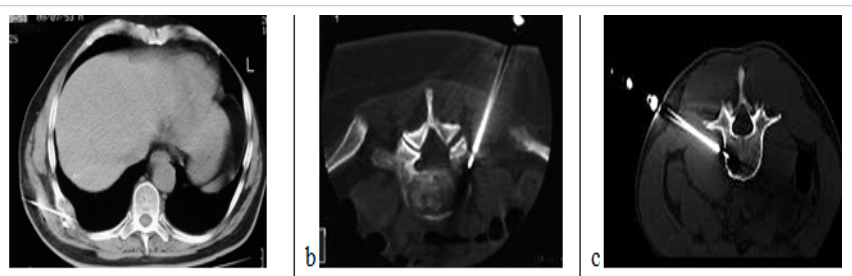

Figure 1: Computed tomography scan of three patients, revealing metastatic lesion due to NSCLC located a) to the rib, b,c) spine. The radiofrequency ablation electrode is imaged within the lesion.

\section{Results}

All patients received NSAIDs, opioids or combined medication before ablation therapy. Pain reduction one day after the procedure was reported in $30 / 32$ patients $(93,7 \%)$. One week after treatment only 3 out of 32 patients were treated with NSAIDs, or a combination of NSAID/low-dose opioids. After four and eight weeks only 1 out of 32 patients received painkillers. One patient died during the 8-week follow-up due to his primary malignancy. None patient reported pain increase. Prior to the procedure, the mean past day BPI score for worst pain was 8.4, mean pain was 7.1, and mean pain interference with daily life 7.6. After RF ablation these scores were reduced to 7, 4.3 and 6.1 one day after the session, dropped to 4.6, 3 and 3.5 after one week, to $3.2,1.8$ and 2 after four weeks and to 2.1, 1.3 and 1.5 after eight weeks respectively [Table 2].

\begin{tabular}{|c|c|c|c|c|c|}
\hline \multicolumn{1}{|c|}{ Table 2: BPI score prior and after RFA } \\
\hline & $\begin{array}{c}\text { Prior } \\
\text { RFA }\end{array}$ & $\begin{array}{c}1 \text { day } \\
\text { after } \\
\text { RFA }\end{array}$ & $\begin{array}{c}1 \text { week } \\
\text { after } \\
\text { RFA }\end{array}$ & $\begin{array}{c}\text { 4 weeks } \\
\text { after RFA }\end{array}$ & $\begin{array}{c}\text { 8 weeks } \\
\text { after RFA }\end{array}$ \\
\hline Worst pain & 8.4 & 7 & 4.6 & 3.2 & 2.1 \\
\hline Mean pain & 7.1 & 4.3 & 3.5 & 1.8 & 1.3 \\
\hline $\begin{array}{c}\text { Mean pain } \\
\text { interference } \\
\text { with daily life }\end{array}$ & 7.6 & 6.1 & 3.2 & 2 & 1.5 \\
\hline
\end{tabular}

The mean past day BPI score for worst pain, for average pain and for pain interference in daily life improved in comparison to pre procedural symptoms $(\mathrm{P}<0.001$, paired $\mathrm{t}$-test $)$ resulting in life quality improvement of all patients from the first week after the procedure up to the 8-week follow-up. None major (hemorrhage, thrombosis of proximal veins) or minor (skin burns, post ablation syndrome) complication occurred all patients. 


\section{Discussion}

Bone metastases represent a prominent source of morbidity due to pain, dysfunction, pathologic fracture and neurovascular compromise. Nearly $80 \%$ of patients experience severe pain before a sufficient palliative treatment plan is initiated [1]. Initial therapeutic options include pain management/analgesia, chemotherapy and/or hormone therapy, radiation therapy, stereotactic body radiotherapy, bone-targeted radiopharmaceuticals, imaging guided percutaneous ablation and surgery [2]. Several factors influence the choice of treatment, including performance status, life expectancy, clinical disease status and the impact of the bone metastasis on quality of life [4].

Medication is the first line treatment for cancer pain, NSAIDs and opioids are the most common medical therapy because they are effective for all types of cancer pain [5,6]. Optimal pain control usually requires titration. Consultation with an anesthesia pain specialist can be considered for integration of interventional procedures.

Radiation therapy is a standard approach for symptomatic bone metastases, achieving pain reduction in 50 to 80 percent, which is complete in up to $30 \%$ of patients. Extensive, painful bone metastases may be treated with single-fraction hemi body irradiation to the upper, lower or mid-body. However, radiation therapy may also cause complications, mostly from damage of adjacent soft tissues [7,8].

Stereotactic Body Radiotherapy (SBRT) is an emerging tool to treat selected patients ( $>6$ month life expectancy, limited visceral metastasis, good performance status) with small volume vertebral involvement and may be particularly helpful for patients who require re-irradiation. SBRT is not suitable for patients with a limited life expectancy, extensive metastatic disease, or symptomatic spinal cord compression due to bone metastasis [9].

Chemotherapy, targeted therapies, and hormone therapy are systemic methods of metastatic cells treatment with low sensitivity, not well tolerated and associated with many complications [5]. Radiopharmaceutical agents vary with regard to the analgesic efficacy, duration of pain palliation, ability to repeat treatments, toxicity and expense [6]. Newer biological or molecularly targeted agents have fewer side effects and may be more tolerable. However, like chemotherapy, they are not associated with immediate pain relief.

Surgical management of bone metastases is typically reserved for lesions with a completed or impending pathologic fracture [10]. In a systematic review of 45 studies addressing the role of surgical management of bone metastases involving the humerus, femur, and pelvis/acetabulum ( $47 \%$ of cases with a pathologic fracture), surgery was associated with significant pain relief in 91 to $93 \%$ of cases, and function was maintained or improved in 89 to $94 \%$ [11]. The rates of perioperative complications and mortality were 17 and 4\%, respectively.

Local ablation is an important therapeutic option for patients who have persistent or recurrent pain attributed to one or a few skeletal sites with small volume disease after palliative $\mathrm{RT}$ and who are not candidates for surgery or re irradiation with stereotactic techniques. Radiofrequency ablation, cryoablation, and Focused Ultrasound (FUS) are all effective ablative treatments for palliation of symptomatic skeletal metastases. The choice of ablation technique should take into account availability, patient preference and local expertise. Prospective, single-arm multicenter trials have shown RFA and cryoablation to be safe and highly effective for treatment of symptomatic skeletal metastases [12-16]. A large randomized, controlled, multicenter phase III trial has shown Focused Ultrasound (FUS) to be effective in the treatment of painful bone metastases [17], confirming results of earlier retrospective reports [18]. Small case series also support benefit from other percutaneous methods of image-guided ablation, including microwave ablation, laser ablation, and irreversible electroporation to treat skeletal metastases, although the data are more limited [19-26]. These studies demonstrate that multiple ablation therapies are effective at palliation of pain due to metastatic skeletal disease. Another center retrospectively reviewed their experience with cryoablation to treat limited metastases from Non-Small Cell Lung Carcinoma (NSCLC) $[27,28]$. Among 24 bone and non-visceral soft tissue metastases from NSCLC, local control was achieved in 87 percent.

Each treatment modality has its advantages and disadvantages, and the choice of ablation technology typically depends on several factors, including interventional rradiologist preference and local expertise [23]. In our study the modality of choice was RFA due to availability, cost and expertise. In $93.7 \%$ of our patients, we observed a considerable immediate reduction of pain, reduction of the use of analgesic medication and improvement of life quality as measured by the BPI score. The clinical result was excellent with total necrosis of the lesion, decrease of the BPI score immediately after the ablation until the 8-week follow-up. The follow-up period for this study was eight weeks; a period sufficient to demonstrate that ablation provides effective palliation. The results of this study are in agreement with previous studies by Callstrom et al. [15] and Thanos et al. [29] revealing better results regarding the immediate pain relief. Pain relief mechanism with RFA is managed with transmission inhibition by destroying sensory nerve fibres in the periosteum and bone cortex; reduction of lesion volume with decreased stimulation of sensory nerve fibres; destruction of tumour cells that are producing nerve-stimulating cytokines and inhibition of osteoclast activity [7]. Thus low conductivity of radiofrequency ablation inside the bone is not a limiting factor. Although a few patients reported mild discomfort during the ablation, none of the sessions was forced to stop due to patient distress.

Complications from ablation of skeletal metastases include injury to structures during applicator placement. Trials of RFA and cryoablation have reported serious complication rates of 0 to $10 \%$ (mostly pain, neurologic compromise, and pathologic fractures) [12-14,29]. None possible complication, including infection haemorrhage, neurological complications, skin burns, or post-ablation syndrome (low-grade fever $\leq 37.8$ myalgias, and malaise) for up to one week after the ablation was reported in our patient group. This appears to be a fairly well-tolerated procedure and the combination of conscious sedation and local anaesthesia is adequate for its needs. As referred to the literature when thermal ablation is applied to vertebral metastasis, the treatment 
volume should be at least $10 \mathrm{~mm}$ away from a neural structure to prevent neurologic complications. According to our experience spinal metastases are not a contraindication for the use of RFA due to the proximity with the spinal cord and nerve root [12-14]

\section{Conclusions}

RFA provides fast and effective ablation of bone metastases originating from NSCLC, with immediate clinical improvement of the patients. It is an available, well tolerated ablation method with minimal complication risk. RF energy remains the dominant modality for thermal tumor ablation in the liver, lung, kidney and bone.

\section{Acknowledgements}

All human and animal studies have been approved by the hospital's ethics committee and have therefore been performed in accordance with the ethical standards laid down in the 1964 Declaration of Helsinki and its later amendments.

Conflict-of-interest statement: All authors declare any conflict interest no honorarium, grant, or other form of payment was given to anyone to produce the manuscript.

\section{References}

1. Brodowicz T, O'Byrne K, Manegold C. Bone matters in lung cancer. Ann Oncol. $2012 ; 23(9): 2215-2222$.

2. Pockett RD, Castellano D, McEwan P, Oglesby A, Barber BL, Chung K. The hospital burden of disease associated with bone metastases and skeletal-related events in patients with breast cancer, lung cancer, or prostate cancer in Spain. Eur J Cancer Care (Engl). 2010;19(6):755.

3. Monfardini L, Preda L, Aurilio G, Stefania Rizzo, Vincenzo Bagnardi, Giuseppe Renne, et al. CT-guided bone biopsy in cancer patients with suspected bone metastases: retrospective review of 308 procedures. Radiol Med. 2014;119(11):852-860.

4. Gough N, Miah AB, Linch M. Nonsurgical oncological management of cancer pain. Curr Opin Support Palliat Care. 2014;8(2):102-111. doi: 10.1097/SPC.0000000000000043

5. Chia SK, Speers CH, D'yachkova Y, Kang A, Malfair Taylor S, Barnett J, et al. The impact of new chemotherapeutic and hormone agents on survival in a population-based cohort of women with metastatic breast cancer. Cancer. 2007;110(5):973.

6. Buga S, Sarria JE. The management of pain in metastatic bone disease. Cancer Control. 2012;19(2):154-166.

7. Nielsen OS. Palliative radiotherapy of bone metastases: there is now evidence for the use of single fractions. Radiother Oncol. 1999;52(2):95.

8. Finlay IG, Mason MD, Shelley M. Radioisotopes for the palliation of metastatic bone cancer: a systematic review. Lancet Oncol. 2005;6(6):392-400. doi: 10.1016/S1470-2045(05)70206-0

9. Lutz S, Berk L, Chang E, Chow E, Hahn C, Hoskin P, et al. Palliative radiotherapy for bone metastases: an ASTRO evidence-based guideline. Int J Radiat Oncol Biol Phys. 2011;79(4):965-976. doi: 10.1016/j. ijrobp.2010.11

10. Bickels J, Dadia S, Lidar Z. Surgical management of metastatic bone disease. J Bone Joint Surg Am. 2009;91(6):1503-1516. doi: 10.2106/ JBJS.H.00175

11. Wood TJ, Racano A, Yeung H, Farrokhyar F, Ghert M, Deheshi BM. Surgical management of bone metastases: quality of evidence and systematic review. Ann Surg Oncol. 2014;21(13):4081-4089. doi: 10.1245/ s10434-014-4002-1
12. Callstrom MR, Charboneau JW, Goetz MP, Rubin J, Atwell TD, Farrell MA, et al. Image-guided ablation of painful metastatic bone tumors: a new and effective approach to a difficult problem. Skeletal Radiol. 2006;35(1):1-15.

13. Goetz MP, Callstrom MR, Charboneau JW, Farrell MA, Maus TP, Welch TJ, et al. Percutaneous image-guided radiofrequency ablation of painful metastases involving bone: a multicenter study. J Clin Oncol. 2004;22(2):300.

14. Dupuy DE, Liu D, Hartfeil D, Hanna L, Blume JD, Ahrar K, et al. Percutaneous radiofrequency ablation of painful osseous metastases: a multicenter American College of Radiology Imaging Network trial. Cancer. 2010;116(4):989.

15. Callstrom MR, Dupuy DE, Solomon SB, Beres RA, Littrup PJ, Davis KW, et al. Percutaneous image-guided cryoablation of painful metastases involving bone: multicenter trial. Cancer. 2013;119(5):1033-1041.

16. Tomasian A, Wallace A, Northrup B, Hillen TJ, Jennings JW. Spine Cryoablation: Pain Palliation and Local Tumor Control for Vertebral Metastases. AJNR Am J Neuroradiol. 2016;37(1):189.

17. Hurwitz MD, Ghanouni P, Kanaev SV, Iozeffi D, Gianfelice D, Fennessy FM, et al. Magnetic resonance-guided focused ultrasound for patients with painful bone metastases: phase III trial results. J Natl Cancer Inst. 2014;106(5). doi: 10.1093/jnci/dju082

18. Catane R, Beck A, Inbar Y, Rabin T, Shabshin N, Hengst S, et al. MR-guided focused ultrasound surgery (MRgFUS) for the palliation of pain in patients with bone metastases--preliminary clinical experience. Ann Oncol. 2007;18(1):163-167

19. Ahrar K, Stafford RJ. Magnetic resonance imaging-guided laser ablation of bone tumors. Tech Vasc Interv Radiol. 2011;14(3):177-182.

20. Carrafiello G, LaganàD, Pellegrino $C$, Fontana F, Mangini M, Nicotera $P$, et al. Percutaneous imaging-guided ablation therapies in the treatment of symptomatic bone metastases: preliminary experience. Radiol Med. 2009;114(4):608-625.

21. Fan QY, Ma BA, Zhou Y, et al. Bone tumors of the extremities or pelvis treated by microwave-induced hyperthermia. Clin Orthop Relat Res. 2003;(406):165-175.

22. Grieco CA, Simon CJ, Mayo-Smith WW, Dipetrillo TA, Ready NE, Dupuy DE. Image-guided percutaneous thermal ablation for the palliative treatment of chest wall masses. Am J Clin Oncol. 2007;30(4):361.

23. Groenemeyer DH, Schirp S, Gevargez A. Image-guided percutaneous thermal ablation of bone tumors. Acad Radiol. 2002;9(4):467-477.

24. Pusceddu C, Sotgia B, Fele RM, Melis L. Treatment of bone metastases with microwave thermal ablation. J Vasc Interv Radiol. 2013;24(2):229-233.

25.Simon CJ, Dupuy DE, Mayo-Smith WW. Microwave ablation: principles and applications. Radiographics. 2005;25:S69-83.

26. Kastler A, Alnassan H, Pereira PL, Alemann G, BarbéDA, Aubry S, et al. Analgesic effects of microwave ablation of bone and soft tissue tumors under local anesthesia. Pain Med. 2013;14(12):1873-1881.

27. Bang HJ, Littrup PJ, Currier BP, Goodrich DJ, Aoun HD, Klein LC, et al. Percutaneous cryoablation of metastatic lesions from non-small-cell lung carcinoma: initial survival, local control, and cost observations. J Vasc Interv Radiol. 2012;23(6):761-769.

28. Callstrom MR, Atwell TD, Charboneau JW, Farrell MA, Goetz MP, Rubin J, et al. Painful metastases involving bone: percutaneous imageguided cryoablation--prospective trial interim analysis. Radiology. 2006;241(2):572-580.

29. Botsa E, Mylona S, Koutsogiannis I, Koundouraki A, Thanos L. CT image guided thermal ablation techniques for palliation of painful bone metastases. Ann Palliat Med. 2014;3(2):47-53. 